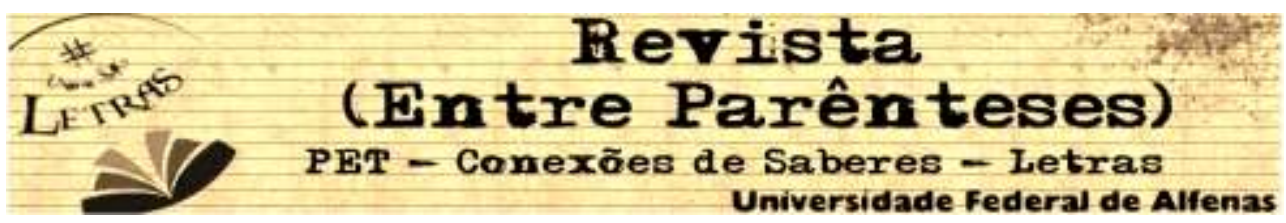

\title{
AS RELAÇÕES ENTRE LITERATURA E HISTÓRIA NO ROMANCE FINISTERRE, DE MARÍA ROSA LOJO
}

\author{
Fernanda Aparecida Ribeiro ${ }^{1}$ \\ Universidade Federal de Alfenas \\ (espanhol.unifal@gmail.com)
}

\begin{abstract}
RESUMO: O romance histórico contemporâneo tem como característica marcante a releitura crítica da história, de modo a evidenciar que o passado histórico não pode ser representado em sua totalidade porque seu resgate provém da leitura do historiador a partir de vestígios - textos, fotos, vídeos, relatos orais, etc. Assim, a literatura reivindica a possibilidade de proporcionar uma leitura do passado, utilizando-se dos mesmos vestígios, e criando um discurso narrativo no qual propõe uma interpretação a partir de um ponto de vista distinto. Assim acontece com o romance Finisterre (2005), da escritora argentina María Rosa Lojo, que trata das lutas entre os espanhóis/argentinos contra os índios da fronteira no século XIX. A leitura atenta da autora leva o leitor a repensar um dos binômios principais que foi instaurado pelos discursos nacionalistas nessa época: civilização e barbárie. $O$ ponto de vista no romance é da personagem feminina que vive em meio ao conflito, conhece o "outro" e, assim, instiga a questão do sujeito cultural argentino.
\end{abstract}

Palavras-chave: Romance histórico; Literatura e História; Literatura e Mulher; María Rosa Lojo; Finisterre.

RESUMEN: La novela histórica contemporánea tiene como característica sobresaliente la relectura crítica de la historia de modo a evidenciar que el pasado histórico no puede ser representado en su totalidad porque el rescate proviene de la lectura del historiador a partir de los vestigios - textos, fotos, videos, relatos orales, etc. Así, la literatura reivindica la posibilidad de proporcionar una lectura del pasado, utilizándose de los mismos vestigios, y creando un discurso narrativo en lo cual se propone una interpretación a partir de un punto de vista distinto. Eso ocurre con la novela Finisterre (2005), de la escritora argentina María Rosa Lojo, que trata de las luchas entre los españoles/argentinos contra los indígenas de la frontera en el siglo XIX. La lectura atenta de la autora lleva el lector a repensar uno de los binomios principales que fue instaurado por los discursos nacionalistas en esa época: civilización y barbarie. El punto de vista de la novela es el personaje femenino que vive en medio del conflicto, conoce el "otro" y, así, instiga la cuestión del sujeto cultural argentino.

Palabras clave: Novela histórica; Literatura e Historia; Literatura y Mujer; María Rosa Lojo; Finisterre.

Finisterre (2005) é um livro da escritora argentina María Rosa Lojo (1954-)2. Trata-se de um romance de tema histórico, um tipo de narrativa que dialoga com a literatura e a história, no qual se sobressaem a reinvenção dos relatos fundadores da Argentina, como o mito de La Cautiva e a dicotomia civilização e barbárie, e o destaque para as vozes daqueles que foram relegados à

1 Profa de Literatura Hispano-americana do Curso de Letras e do Programa de Pós-Gradução Mestrado em História Ibérica da Universidade Federal de Alfenas.

2 Esse texto é parte da comunicação apresentada, com o mesmo título, no III Encontro Internacional de Letras "Língua, linguagens, culturas e ensino: o cruzamento de fronteiras imaginárias", as I Jornadas de Linguagens e Cultura", na UNIOSTE, nos dias 07 a 11 de outubro de 2014. Revista (Entre Parênteses) 


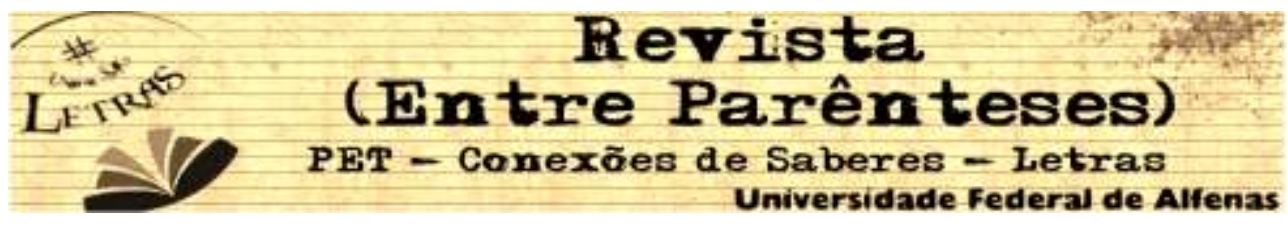

margem da sociedade e também do discurso histórico: as mulheres, os galegos, os indígenas, entre outros.

Primeiramente, para uma análise mais aprofundada sobre o gênero narrativo, torna-se imprescindível um breve resumo da travessia realizada pela literatura e a história, desde o século XIX, na Europa, quando o escritor escocês Walter Scott iniciou um tipo de narrativa literária conhecida como romance histórico - segundo a teoria de Lukács (1977), até suas modificações em meados do século $\mathrm{XX}$ pela literatura latino-americana.

Na Europa do século XIX, palco do nascimento e esplendor inicial do romance histórico, existe uma concepção positivista da história que leva o romance histórico a incorporar a história sem questionamento ou crítica, há a "crença na possibilidade de figuração realista do passado como passo decisivo para a compreensão e resolução dos conflitos do presente" (FIGUEIREDO, 1998, p. 480). No entanto, a América Latina, que vive o período das independências políticas e da invenção de uma tradição literária, importa a visão de história europeia, o que não engloba seus problemas de compreensão da realidade e busca de identidade.

As características apontadas por Lukács a partir da análise dos livros de Walter Scott e dos demais romances históricos da Europa do século XIX, narrativas que ele denomina "romances históricos clássicos", são: a existência de uma ambientação estritamente histórica, como um telão de fundo do enredo, no qual se movem as personagens; o fato de as personagens principais serem fictícias e as personagens históricas serem apresentadas como eram vistas pela história e atuando nas ações documentadas (praticamente em segundo plano); e a visão otimista da história a partir da ideia de progresso, ignorando a história de conflitos. Tais peculiaridades são superadas ao longo do século XIX e início do século XX por autores que "adaptam" seus livros conforme a visão de mundo que possuem.

Por isso, tal modelo clássico é superado na América em meados do século XX, quando a problematização da reinterpretação do passado latinoamericano leva os escritores do continente a procurarem recursos literários que traduzam a memória e a visão de história que possuem, que é muito distinta da visão otimista e positivista da Europa.

Revista (Entre Parênteses) 


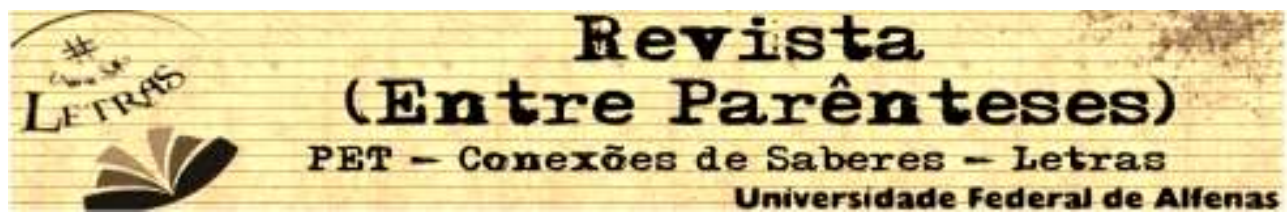

Esse novo gênero narrativo diferencia-se em vários aspectos do romance histórico clássico teorizado por Lukács. Nessa nova modalidade de romance histórico ou, como será nomeado neste texto, romance histórico contemporâneo, encontram-se várias singularidades como a intertextualidade, a ficcionalização dos personagens históricos e a releitura crítica, e algumas vezes conflitiva, da história com o objetivo de proporcionar uma nova perspectiva da interpretação do passado.

Muitos são os estudos sobre esse tipo de romance na América Latina, especialmente após as décadas de setenta e de oitenta, quando o gênero ganha características que se distinguem do modelo do século anterior. De todas as características que os críticos levantam sobre o romance histórico contemporâneo, acredita-se que uma das principais seja aquela que Magdalena Perkowska aponta na introdução de seu livro, Historias híbridas (2008, p. 42):

[...] los novelistas dibujan un nuevo mapa para el concepto de la historia y su discurso. Vista desde esta perspectiva, la novela histórica latinoamericana no cancela la historia sino que redefine el espacio declarado como "histórico" por la tradición, la convención y el poder, postulando y configurando en su lugar las historias híbridas que tratan de imaginar otros tiempos, otras posibilidades, otras historias y discursos.

Talvez esse seja a principal finalidade dos autores latino-americanos: realizar uma leitura atenta, pormenorizada e crítica da história, não com o objetivo de anulá-la, mas sim de recolocar a história em um espaço em que se permitem outros tempos, várias versões e diversos discursos que contribuem na interpretação do passado.

O escritor Mario Vargas Llosa, em seu texto "La verdad de las mentiras" (1990, p. 7), faz uma defesa de como a ficção (tida como "fingimento", "invenção"): "En efecto, las novelas mienten - no pueden hacer otra cosa - pero ésa es sólo una parte de la historia. La otra es que, mintiendo, expresan una curiosa verdad, que sólo puede expresarse disimulada y encubierta, disfrazada de lo que no es".

Assim como Vargas Llosa atenta para o fato de os romances trabalharem a ficção como uma forma de abordar o mundo, como uma visão particular de compreender a realidade, e de expressar a sua leitura própria, a chamada "curiosa verdade", Mercedes Giuffré (2004, p. 23-24) também informa que no romance 


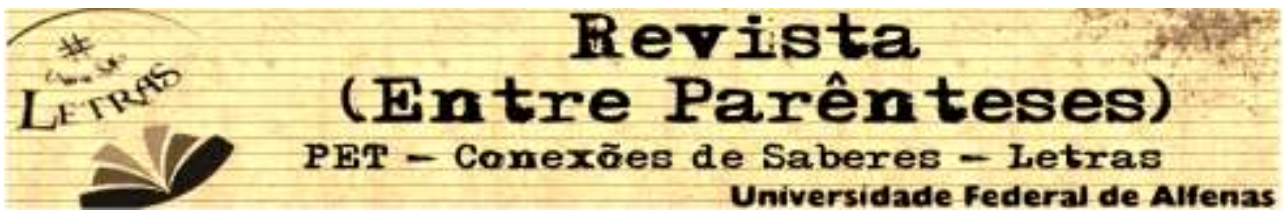

histórico não há mentira, mas:

(...) es una forma de pensar el pasado y de repensar la escritura de la historia. No miente sino que interpreta, e intenta comprender el presente que resulta del pasado, valiéndose de las herramientas que aporta la imaginación.

Um dos primeiros críticos do romance histórico contemporâneo foi Seymour Menton que, no livro La nueva novela histórica de la América Latina (1993), assinala seis características dos romances históricos contemporâneos, que ele nomeia como Novo Romance Histórico. Dentre elas, destaca-se a impossibilidade de conhecer a realidade histórica por completo, pois o que ficou do passado são vestígios - relatos, memórias, fotos, textos, entre outros - que são interpretados conforme a ideologia ou objetivo dos historiadores que investigam tal assunto.

Esse mesmo caminho de interpretação crítica do passado é seguido pelas escritoras da América Latina, segundo Gloria da Cunha na introdução do livro La narrativa histórica de escritoras latinoamericanas (2004), problematizando a representação do passado desde uma perspectiva crítica, oferecendo novas leituras para as versões oficiais que a historiografia legitimou.

Em Finisterre, María Rosa Lojo coloca em evidência o relato de vida de duas mulheres, Rosalind e Elizabeth, personagens fictícias que vivem uma história muito semelhante a de diversas mulheres na América. Existe, assim, uma ideologia que permeia todo o romance da escritora e que pode ser analisado a partir dos princípios básicos da crítica literária feminista, que discute a posição e a representação da mulher nos textos literários escritos tanto por homens como por mulheres e que problematiza as causas da opressão feminina frente ao patriarcado.

A Crítica Feminista teve como pressuposto inicial que a experiência da mulher como leitora e como escritora poderia ser distinta da experiência masculina, o que resultaria em mudanças significativas no campo intelectual, marcado pelo rompimento de paradigmas e pela descoberta de novos caminhos. Ou seja, algumas das intenções dessa crítica é debater o espaço relegado à mulher na sociedade e desconstruir a oposição homem/mulher, entre outras.

Segundo Lúcia O. Zolin (2005, p. 189), a Crítica Feminista tem sua 


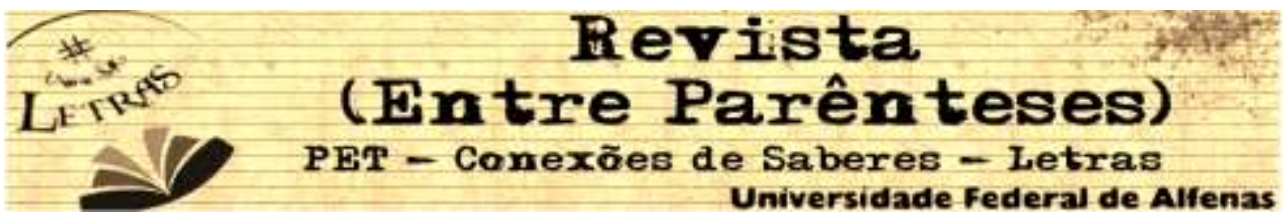

origem com a publicação de Sexual Politics, de Kate Millet, em 1970, uma obra que "traz à tona discussões acerca da posição secundária ocupada pelas heroínas dos romances de autoria masculina, como também pelas escritoras e críticas literárias". No seu início, o foco era desmascarar os conceitos do patriarcado presentes na prática literária canônica, reforçando a subordinação feminina como algo próprio de sua natureza e não como uma prática imposta pelas normas sociais.

Em sua tese, Kate Millet parte da discussão de que o patriarcado gera a opressão feminina por meio de um rígido sistema que distingue os papéis sexuais, na qual tudo o que se refere ao papel masculino é "universal" e "oficial", oprimindo o lado feminino. As feministas consideram a diferença de gênero como fator essencial para marcar a conduta e a relação entre homens e mulheres, demonstrando que o gênero é uma construção histórico-social. Assim, elas pretendem fazer com que a posição da mulher na sociedade seja aceita não em segundo plano ou como inferior, mas, sim, tão importante e "normal" como a do homem, respeitadas as diferenças entre eles.

Uma tendência mais contemporânea, conforme Zolin, é conceituar a noção de gênero não como oposição binária homem/mulher, mas como uma característica variável de "posicionalidades discursivas sexuais", isto é, "uma subjetividade múltipla e não unificada, capaz de abarcar o que as estruturas da representação de gênero deixam de fora, por exemplo, os espaços sociais ou os discursos produzidos nas margens" (ZOLIN, 2005, p. 200-201). Nesse sentido, o conceito de gênero não está vinculado à oposição homem/mulher, mas a discursos concebidos dentro de certos contextos político-sociais.

Dos três enfoques feministas atuais - o britânico, orientado pelas teorias marxistas; o francês, que se baseia na psicanálise; e o estadunidense, que é essencialmente textual - destaca-se aqui o último por ter o foco no texto literário. Uma importante representante é Elaine Showalter, que analisa os textos de escritoras inglesas do século XIX, em “A Literature of Their Own” (1986), e propõe uma classificação das fases históricas dessas subculturas literárias escritas por mulheres dos Estados Unidos: feminine, feminist e female.

A primeira, que se pode traduzir por "feminina", é o momento em que as 


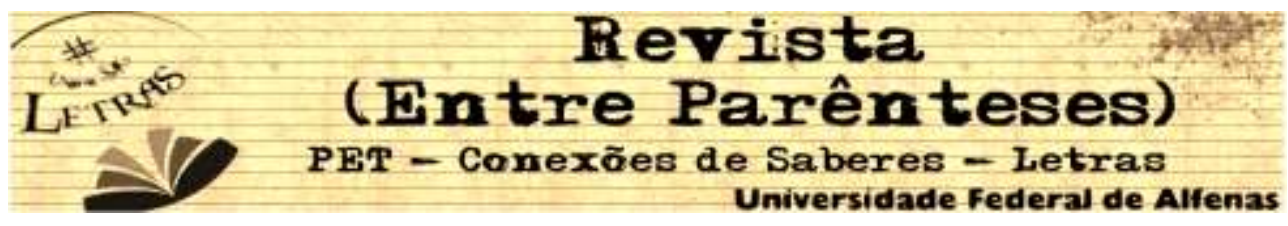

autoras seguem o padrão e os modelos da tradição da literatura dominante (leia-se: masculina), e outorgam às suas personagens femininas papéis secundários. $A$ segunda, traduzida como "feminista", é uma fase de protesto, de sublevação da autora frente à condição subordinada da mulher na sociedade e na sua representação na literatura; contudo, ela não consegue se libertar completamente da literatura dominante e de seus modelos. Já a última fase, muitas vezes traduzida para o português como "da mulher" (no espanhol "autodescubrimiento"), aponta para uma identidade e autonomia feminina, na qual as mulheres encontram um conhecimento de si mesmas e dos problemas em questão e o interesse se volta para os textos escritos por elas mesmas. Essa classificação pode ser válida para literaturas escritas por mulheres de outros países, como do Brasil e da Argentina.

Em um texto sobre as escritoras da Argentina do final do século XX, Gardarsdóttir (2005, p. 173) afirma que no "contexto de la literatura argentina finisecular escrita por mujeres debemos necesariamente partir de las nociones de protesta (feminista) y de descubrimiento (identidad)". Isto é, as escritoras argentinas já superaram a fase feminina e estão em trânsito entre a fase de protesto e do autodescobrimento.

É nesse contexto que se situa a autora María Rosa Lojo, trabalhando em seus textos os espaços de fronteira - como os limites entre a literatura, a história e a memória - e também a ruptura da dualidade de conceitos, como a civilização e a barbárie, a relação do homem e da mulher e seus papéis na sociedade. Assim, ela propõe uma nova interpretação do passado histórico a partir do olhar feminino de suas personagens. Essas personagens vivem em conflito consigo mesmas e com o mundo ao redor, buscando constantemente a sua identidade em meio a um mundo dominado pelos homens.

No romance Finisterre, a luta dessas mulheres representa a vida dos argentinos e tem um espaço físico que é o seu símbolo, o deserto, uma "extensão superficial, estéril, debaixo da qual tem de ser procurada a Realidade" (CHEVALIER - p. 331). Ou seja, é um lugar árido que oculta a realidade argentina: o enfrentamento dos grupos sociais que lutam entre si pela sobrevivência e que buscam na terra a sua identidade nacional. 


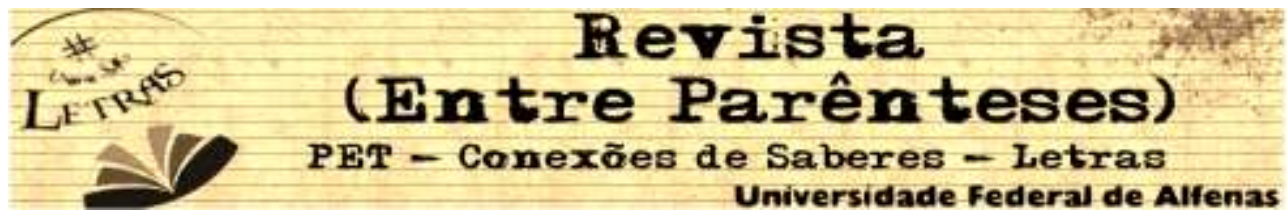

Por meio da voz e do olhar feminino, a autora argentina resgata um tema tradicional na literatura de seu país e o converte em material artístico, desenhando um novo conceito de escritura, ao mesmo tempo que postula as "histórias híbridas", segundo o termo cunhado por Magdalena Perkowska (2008). María Rosa Lojo é uma escritora que sabe reinventar a literatura de seu país por meio da ficção e da história e a retomada do mito de La Cautiva é um exemplo disso.

Na América Hispânica, encontramos esse mito na história e na literatura argentina, desde o período da Colônia, com a crônica de conquista La Argentina o Historia del Descubrimiento, Conquista y Población del Río de la Plata (1612), conhecida atualmente como La Argentina Manuscrita, de Ruy Díaz de Guzmán. No capítulo VII, "De la muerte del capitán don Nuño de Lara, y su gente; y lo demás sucedido", o autor narra a lenda de Lucía Miranda, a esposa de Sebastián Hurtado.

No texto de Díaz de Guzmán, a violência surge por parte dos indígenas, que adentram no território dos espanhóis, matam os homens e capturam a mulher desejada. Esse gesto deles é visto como traição, pois o autor sublinha que a convivência entre índios e espanhóis era pacífica. Assim, para o cronista, as vítimas são os espanhóis, que sofrem a agressão indígena e a morte é uma forma de redenção aqueles que levavam o cristianismo aos infiéis.

Com o poema "La Cautiva" (1837), de Esteban Echeverría, o tema volta a aparecer na literatura argentina no momento do Romantismo, com um novo enfoque. Os personagens do relato são María y Brian e é ela quem mata o índio e este não consegue possuí-la. Todavia, o casal não consegue voltar a civilização e eles morrem no deserto. Pode-se dizer que o corpo da cativa, segundo Semilla Durán (p. 02), "no puede anular la historia y queda fuera de la civilización, pero no ha sido poseído por el indio y es territorio sacralizado de resistencia”.

Há dois pontos no texto de Echeverría que merecem ser enfatizados: 1) a descrição dos indígenas e 2) a posse do corpo da mulher. A representação negativa do índio coincide com o processo de "civilização" da Argentina e da apropriação das terras dos indígenas por aqueles que se consideravam donos do país, e o corpo da personagem María se torna um símbolo de desonra, uma zona de disputa e poder, representando a Argentina em luta contra a "barbárie" dos índios. 


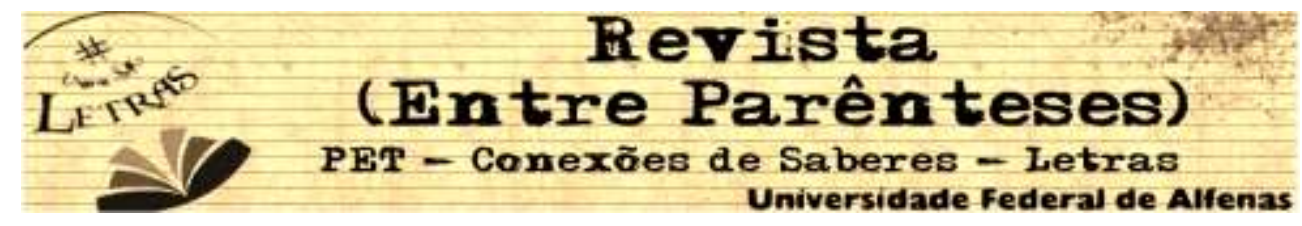

Já no século XX, o escritor Argentino Jorge Luis Borges (1899-1986) escreveu um conto intitulado "Historia del guerrero y la cautiva". Nesse relato, o narrador faz um paralelo entre o personagem Droctulft, um guerreiro lombardo que renuncia aos seus para defender a "outra" cidade que estava atacando, e a descrição da mulher inglesa, cativa nos pampas, que preferiu viver com os indígenas a regressar a cidade ("civilização").

Os dois personagens borgianos vivem uma situação de fronteira, conhecem o "outro lado", do desconhecido, sentem-se fascinados pelo Outro, vivem e adotam a outra Cultura. Como destaca Beatriz Sarlo (2001):

Borges encuentra en la historia de la cautiva el espejo de una historia anterior. Pero también un perfil reflejado de la condición americana: vivir en la frontera (que también es una orilla) es condición no sólo de la historia de la cautiva sino de su propia historia y (por desplazamiento) de la literatura argentina.

O enredo de Finisterre se passa no século XIX, na Argentina, época das lutas da Independência, da ditadura de Juan Manuel de Rosas e a conquista dos Pampas (Campanha do Deserto). Grande parte do romance está escrito sobre forma de cartas, principalmente as cartas que Rosalind escreve a Elizabeth. Nelas, Rosalind conta sua história, descreve sua viagem ao Rio da Prata com o marido, como foi presa e se tornou cativa dos índios ranqueles e, ao final, como nasceu Elizabeth. Ambas as personagens e suas histórias são fictícias. Contudo, o que se coloca em primeiro plano é o contato com a cultura indígena e a quebra de valores/preconceitos atribuídos aos índios.

Assim, a autora também quebra várias binariedades, como: civilização e barbárie, feminino e masculino, campo e cidade, cultura europeia e cultura indígena, entre outros, demonstrando que os elementos das dicotomias não são contrários, são duas formas distintas de enxergar o mundo, mas sem que haja o superior e o inferior, o melhor e o pior, etc.

Para conseguir a quebra desses paradigmas, a autora utiliza uma narradora em primeira pessoa, que descreve sua própria experiência como cativa dos índios. Rosalind consegue se adaptar à cultura indígena, ao contrário de Oliver, pai de Elizabeth, e doña Ana. É possível que isso aconteça porque Rosalind é da 


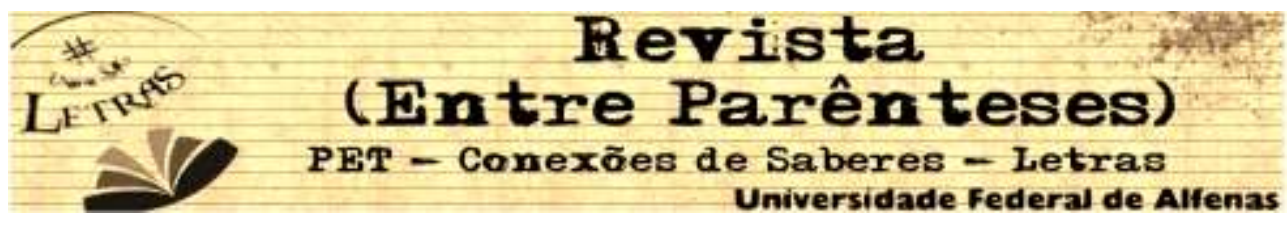

Galícia, Espanha - que se considerava (ou era considerado) um povo à margem da sociedade espanhola. Além disso, Rosalind sofre a submissão feminina frente à autoridade masculina, típico da sociedade patriarcal do século XIX. Assim, ela consegue assimilar melhor uma cultura alheia à sua, também vista como inferior.

Nesse sentido, o romance problematiza a história da Argentina ao questionar a visão eurocêntrica, branca, civilizada, cristã, machista da sociedade espanhola e portenha. E oferece uma nova visão da cultura indígena, discursando sobre seus costumes e negando o papel de selvagem atribuído aos índios.

Mesmo que o romance seja escrito com vários personagens fictícios, há vários outros que são recriados a partir de modelos reais. Entre eles Baigorria (militar argentino, participante das guerras civis da Argentina, viveu nas "tolderías" indígenas, tornando-se, inclusive, cacique dos índios ranqueles), Manuelita Rosas (filha do ditador argentino Juan Manuel de Rosas), Oscar Wilde (escritor irlandês), entre outros mais.

A historiografia se faz presente na narrativa literária por meio das histórias das guerras da independência e da Campanha do Deserto, presentes nas descrições das cartas de Rosalind. A história se faz presente na vida das personagens, mudando seu destino.

Com o recurso de utilizar duas personagens femininas (Rosalind e Elizabeth), a autora denuncia que as vozes femininas foram silenciadas pela história. E por intermédio dessas mesmas vozes, Lojo reinventa a história e a literatura de seu país, pois resgata não só datas e dados históricos, mas temas e gêneros textuais recorrentes da Argentina.

Segundo Marcela Crespo Buiturón (2010), a autora argentina não tem a finalidade de apresentar uma realidade diferente sobre a questão da cultura nacional, mas sim tem a intenção de abordá-la de modo mais aberto. O mesmo acontece com as dicotomias encontradas no romance. A autora não relativiza nenhuma delas, principalmente a dicotomia civilização-barbárie (como fez a literatura hispano-americana desde meados do século $X X)$. Ao contrário, a autora reformula cada dicotomia e o resultado não são dois termos opostos que se anulam e que não conseguem viver no mesmo plano, mas elementos complementários, que 


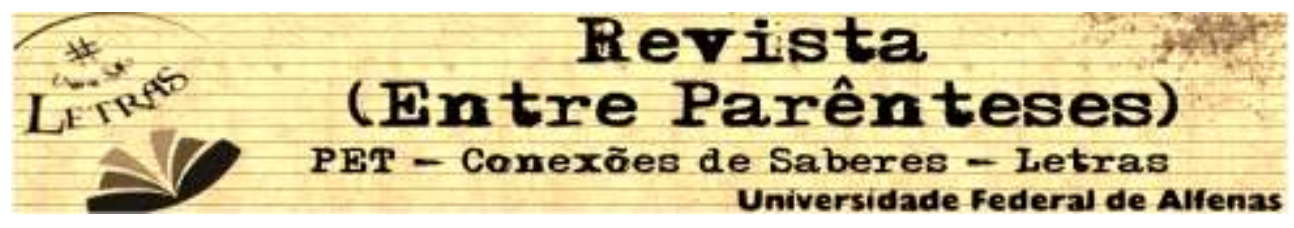

estão no âmago de cada cultura e se alternam, pondo em evidência a realidade multifacetada do mundo.

Concluímos que María Rosa Lojo emprega os discursos cânones da história e da literatura de seu país para propiciar uma discussão dos mesmos por meio de um olhar crítico, na qual se avulta a questão da busca do sujeito cultural argentino.

\section{REFERÊNCIAS}

BORGES, Jorge Luis. Obras completas. 3. ed. Buenos Aires: Emece, 2010. 4 v.

CHEVALIER, Jean; GREERBRANT, Alain. Dicionário dos símbolos: mitos, sonhos, costumes, gestos, formas, figuras, cores, números. Trad. Vera da Costa e Silva et al. 17. ed. Rio de Janeiro: José Olympio, 2002.

CRESPO BUITURÓN, Marcela Gladys. Andar por los bordes. Entre la historia y la ficción: el exilio sin protagonistas de María Rosa Lojo. Alicante: Biblioteca Virtual Miguel de Cervantes, 2009.

CUNHA, Gloria da (Org.) La narrativa histórica de escritoras latinoamericanas. Buenos Aires: Corregidor, 2004.

DIAZ DE GUZMÁN, Ruiz. La Argentina o Historia del Descubrimiento, Conquista y Población del Río de la Plata. Buenos Aires: Casavalle, 1882. Retirado de < http://www.memoriachilena.cl/602/w3-article-9553.html>. Acesso em 29 março 2015. ECHEVERRIA, Esteban. El matadero: La cautiva. 11. ed. Madrid: Catedra, 2009.

FIGUEIREDO, Vera F. de. Da alegria e da angústia de diluir fronteiras: o romance histórico hoje na América Latina. Cânones e contextos: Anais do 5․ Congresso ABRALIC. Rio de Janeiro, ABRALIC, 1998, vol. 1. p. 479-486.

GARDARSDÓTTIR, Holmfrídur. La reformulación de la identidad genérica en la narrativa de mujeres argentinas de fin de siglo XX. Buenos Aires: Corregidor, 2005.

GIUFFRÉ, Mercedes (Org.) En busca de la identidad (La Novela Histórica en Argentina). Buenos Aires: Ed. del Signo, 2004

LOJO, María Rosa. Finisterre. Buenos Aires: Sudamericana, 2005.

LUKÁCS, Georges. La novela histórica. Trad. Jasmim Reuter. 3.ed. México: Era, 1977.

MENTON, Seymour. La nueva novela histórica de la América Latina, 1949-1992. México: FCE, 1993.

PERKOWSKA, Magdalena. Historias híbridas: la nueva novela histórica latinoamericana (1985-2000) ante las teorías posmodernas de la historia. Madrid: Iberoamericana; Frankfurt am Main: Vervuert, 2008.

SARLO, Beatriz. Jorge Luis Borges: um escritor na periferia. São Paulo: lluminuras, 2008.

SHOWALTER, Elaine. A literature of their own. In: EAGLETON, M. (Ed.). Feminist literary theory: a reader. Cambridge, Mass.: Blackwell. 1986. p. 11-15.

VARGAS-LLOSA, Mario. La verdad de las mentiras. In: La verdad de las mentiras. Ensayo sobre literatura. 2.ed., Barcelona: Seix Barral, 1990. p. 7-18. 


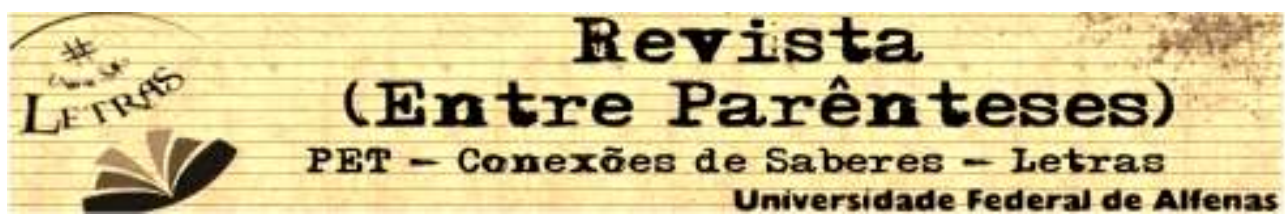

ZOLIN, Lúcia O. Crítica feminista. In: BONNICI, Thomas; ZOLIN, Lúcia O. (Org.) Teoria literária: abordagens históricas e tendências contemporâneas. 2. ed. Maringá: Eduem, 2005. p. 181-203. 